approaches is less than 0.5 sec. and that of the longitudinal frames is of the order of $0.25 \mathrm{sec}$. A factor contributing to the safety of the longitudinal frames against resonance is the varying heights of the columns, each of which has a natural period of its own different from the others. Tunnel anchorages have been used. The principal mass of the bridge is contained in the main-span trusses and the floor, and this mass would produce the greatest transverse earthquake force on the towers at the level of the trusses. The cables have a small mass but transmit heavy loads to the towers. The earthquake forces on the towers from the cables would be small, and the conservative design of the bridge was not affected by the assumed earthquake forces.

\section{Distribution of Typhus}

According to an editorial in the March issue of the Boletin de la Oficina Sanitaria Panamericana the Panamerican Committee on Typhus and other Rickettsial Diseases set up by the eleventh Panamorican Congress held in Rio de Janeiro in September 1942 has come to the following conclusions. With improvement in the methods of investigation the number of cases and the extent of the geographical areas are becoming more apparent. In Chile and more recently in Bolivia and Columbia there have been several epidemics of typhus. Sporadic cases or small epidemies have been repeatedly notified in the Argentine, Brazil, Peru, Ecuador and Venezuela, while in Central America serious outbreaks have been reported in Guatemala as well as cases in El Salvador, Honduras and most of the Caribbean Islands such as Cuba, Puerto Rico and Jamaica. These diseases form one of the major health problems in some parts of Mexico and the United States, and cases have also been seen in Canada. The rickettsiases found in America may be classified into the following four groups : (1) epidemic, classic, European or louseborne; (2) endemic, murine or flea-borne ; (3) Rocky Mountain spotted fever; and (4) $Q$ fever or nine mile fever, Japanese river fever or tsutsugamushi apparently not found hitherto on the American continent. The problem is particularly serious at the present time owing to the War, the rapid transporta. tion of large numbers of persons to and from infected zones and the difficulty of enforcing maritime and aerial quarantine.

\section{Earthquakes Registered in Spain}

DurING May and Juno 1943, forty-five earthquakes and earth tremors were registered by the five Wiechert seismographs at the Observatory at Toledo, according to provisional bulletins just received. During May there were sixteon shocks, the strongest recording being on May 25, when an earthquake beginning with an unidentified emergent pulse at $23 \mathrm{~h} .22 \mathrm{~m}$. $23 \mathrm{~s}$. attained a maximum amplitude of $480 \mu$ on May 26 at $00 \mathrm{~h} .09 \mathrm{~m} .17 \mathrm{~s}$. An earthquake with an estimated depth of focus of $230 \mathrm{~km}$. began recording with iPze at $17 \mathrm{~h} .29 \mathrm{~m}$. 54s. on May 2. During June there were twenty-nine shocks registered. The greatest registration was on June 13, when an earthquake, beginning with $i P z$ at $5 \mathrm{~h} .24 \mathrm{~m}$. 56s., attained a maximum amplitude of $270 \mu$ at $6 \mathrm{~h}$. $05 \mathrm{~m}$. This shock had a depth of focus of $100 \mathrm{~km}$. The shock of June 20, which was reported as destructive at Adapazar in Turkey, first registerod at $15 \mathrm{~h} .38 \mathrm{~m} .29 \mathrm{~s}$. and attained a maximum amplitude at Toledo of $41 \mu$ at $15 \mathrm{~h} .5 \mathrm{~lm}$. (Nature, July 3, p. 17).

\section{Ciencia}

AN editorial note in tho first issue for 1942 of Ciencia: Revista hispano-americano de Ciencias puras $y$ aplicadas (published in Mexico) expresses the hope that its publication, interrupted for a time, will be regular and punctual in the future. Issues for the first half of 1942 deal with a great variety of subjects, some of cultural interest, others of a practical and technical character, and in addition, it contains short items of scientific importance from a great number of countries. Of special interest is a series of articles (not yet completed) by Prof. B. Cabrera, of the National University of Mexico, entitled "El Atomismo y Su Evolucion", which provide an excellent account of the developments in our knowledge of atomic physics from the days of Democritus and Leucippus up to modern times. Dr. Honorato Castro contributes an article on the determination of the distance between two points on the earth's surface with sufficient accuracy to serve the needs of aviators. A spherical earth is assumed in the first case, and then it is shown how corrections can be applied when an ellipsoidal earth is considered. Biological and medical subjects aro prominent, and among the latter may be noticed an important article by Dr. S. Obrador Alcalde, with the title, "Mecanismos Neurales De Los Ritmos Electricos De La Corteza Cerebral". The author, who is connected with the Laboratory of Medical and Biological Research, School of Medicine and Institute of Neuro-Psychiatry, Mexico, deals with investigations. These few references will suffice to show the scope of the journal, and it may also be mentioned that a considerable amount of space is devoted to reviews of scientific works.

\section{Announcements}

Dr. A. H. Rosenthal, well known as a physicist and clectronic engineer, has been appointed director of research and development of Scophony Corporation of America. Dr. Rosenthal has been connectod with Scophony, Ltd., of London, for several years, and in his present position will head a group of scientific men and engineers engaged in research and development of fundamental inventions, not only in television, but also in the ever-widening field of electronics, including various applications of supersonics.

The inaugural meeting of the X-Ray Analysis Group of the Institute of Physics will be held, by invitation of the Manchester and District Branch of tho Institute, in the Physics Department of the University of Manchester on October 16. Sir Lawrence Bragg will open the meeting with a lecture on "The Physical Optics of X-Ray Analysis", which will be followed by four short papers and an exhibition of $\mathrm{X}$-ray apparatus relating to industrial problems.

The late Sir Horace Boot, the distinguished engineer, has bequeathed $£ 5,000$ to the Institution of Civil Engineers and $£ 1,000$ each to the Institutions of Mechanical and Electrical Engineers.

ReFerence was made in Nature of September 25 (p. 352) to the new American publication, Mathematical Tables and Aids to Computation. We are asked to state that the agent in Great Britain for this periodical is the Scientific Computing Service, Ltd., 23 Bedford Square, London, W.C.1 (subscription $£ \mathrm{l}$ ). 